\title{
Marking time and sounding difference: Brubeck, temporality and modernity
}

\author{
ANDY BIRTWISTLE \\ Department of Media, Canterbury Christ Church University, Canterbury CT2 7HD, UK \\ E-mail: andy.birtwistle@canterbury.ac.uk
}

\begin{abstract}
In critical writing on the music of Dave Brubeck, little attention has been paid to the use of polyrhythm, despite the fact that this has been central to Brubeck's approach to jazz since the late 1940s. Focusing on work recorded by the 'classic' Dave Brubeck Quartet, the article aims to re-evaluate Brubeck's use of polyrhythm by situating it within a cultural history of modernity, rather than the established discourses of jazz musicology. The article revisits the early 1960s to reconstruct the context provided for the music not only by articles printed in the music press, but also by news stories and features run in the popular press, and by the visual signifiers that coalesce around Brubeck. Articulated through the key tropes of modernity and difference, the press's construction of Brubeck during this period signals the broad cultural context of Modernism as an alternative frame within which his musical practice might be usefully situated. The article explores how two key cultural artefacts emerging from this context - Brubeck's Oakland home, and the Miró canvas featured on the cover of the album Time Further Out - might serve to provide a productive means by which to re-evaluate the radical potential of Brubeck's polyrhythm.
\end{abstract}

\section{Introduction}

I wanted to do things polyrhythmically because I thought that jazz was much too tame. The way I wanted to set up the group was that the drummer would be playing one rhythm, the bass player another rhythm, and Paul [Desmond] and I could play in either of those rhythms or a new rhythm ... it's time that jazz musicians take up their original role of leading the public into more adventurous rhythms.

Dave Brubeck 1961 ${ }^{1}$

In his next piece, an original called 'Raggy Waltz', he blinded everyone with the science of playing a solo in common time against a rhythmic background of waltz time, an aspect of rhythmic virtuosity having not the remotest connection with the rhythmic vitality of jazz.

Benny Green 1961

Listening to the music of the 'classic' Dave Brubeck Quartet some four decades after it disbanded, it is perhaps easy to forget that Brubeck and his music were once quite controversial. Both the passage of time and the accessibility of Brubeck's music have tended to deflect critical attention from the potentially radical and experimental 
nature of certain aspects of his work. In particular, the temporal experimentation in polyrhythm - which has been a fundamental aspect of his approach to music throughout his career - has suffered critical neglect. While reference is often made to Brubeck's use of adventurous time signatures, and to his extensive use of block chords, there is little critical commentary that assesses the significance of his polyrhythmia within the scope of jazz musicology, let alone within a broader cultural frame.

My aim in this article is provide a fresh perspective on Brubeck's use of polyrhythm by resituating this aspect of his music within a broader art-historical and cultural context than is normally the case in musicological studies of his work. Focusing primarily on the Quartet's work in the late 1950s and early 1960s, I aim to relocate Brubeck's polyrhythmia within a cultural history of modernity, looking beyond its relationship to the dominant paradigms of western art music and American jazz to assess its significance. In the absence of any substantial critical commentary dating from, or relating to, this period, the methodological question arises as to how exactly we might recover and contextualise this particular aspect of Brubeck's work. What I argue here is that in order to understand Brubeck's polyrhythm we need to return to the early 1960s to reconstruct the context provided for the music not only by articles published in the music press, but also by the news stories and features that appeared in the popular press and, equally importantly, through the visual signifiers that coalesce around Brubeck and his music. That is, articles, photographs and album artwork of this period all provide a resonating chamber for the music which allows us to think through the significance of Brubeck's polyrhythmia in the absence of direct critical commentary. Key to understanding this neglected aspect of Brubeck's musical oeuvre is the way in which Brubeck himself is constructed in terms of difference, an essential part of which is an implied or overt association with Modernism. However, the Modernist context to which I refer is not jazz Modernism, but rather, a broader art historical milieu. Clustering around Brubeck and his music during the 1950s and early 1960s are a set of images and ideas that reflect, refract and articulate aspects of the music that seemed to fall on deaf ears when it came to music journalism and criticism.

\section{Critical commentary on polyrhythm}

Brubeck has consistently identified polyrhythm alongside polytonality as key elements of his music: 'My whole idea in jazz ... is superimposing rhythm on rhythm, and harmony on harmony' (The Guardian 1958). His justification for the adoption of these techniques - such as his comment to Ralph J. Gleason that 'it's time that jazz musicians take up their original role of leading the public into more adventurous rhythms' (Jazz Casual 1961) - typically suggest a musical praxis underpinned or rationalised by a Modernist faith in progression. This take on the progressive nature of polyrhythm is echoed in a statement that dates his use of the technique back to the late 1940s, and his work with the short-lived Dave Brubeck Octet: 'When you listen to the old octet, you'll hear a lot of polyrhythm ... it was a very humorous situation, because the critics would say we couldn't play anything in the same tempo, so they weren't ready for what we were doing at all' (Storb and Fischer 1994, p. 33). Yet despite Brubeck's comments on the early critical response to his use of polyrhythm, if one returns to reviews and articles written when 
the Quartet was at the height of its success and fame in the late 1950s and early 1960s, there is scant reference to the device, beyond the occasional recognition of its place in his musical oeuvre. Thus an early reference to polyrhythm in a 1959 concert review published in the Winston-Salem Journal simply states: 'During the performance Brubeck mixed concert style Chopin with his own style of jazz: improvised on a base of Bach; pitted members of the quartet against each other as one played three-four time and another played four-four' (Preslar 1959). As Preslar's brief commentary indicates, Brubeck' s polyrhythmia, when mentioned at all, is simply seen as part of a package, and is rarely singled out for particular attention in the way that his use of 'unusual' time signatures is, for example, or his percussive use of block chords.

While pieces like those by Preslar are positive in their location of polyrhythm within a broader set of experimental approaches to jazz, and certainly respectful of the explanations of the music given by Brubeck in interviews of the time, when situated within Brubeck's departures from established jazz norms, polyrhythm can equally be conceived in terms of failure. Thus The Gramophone comments on Brubeck's 1961 symphonic jazz project, Dialogues For Jazz Combo And Orchestra, 'his relationship to the quartet's rhythm section occasionally becomes so oblique ... the work virtually becomes a three-part dialogue' (Fox 1961, p. 461). For Benny Green (1961), the Quartet's polyrhythmic superimposition of time signatures is simply a failure as jazz, a departure from jazz norms that results in a complete loss of the music's rhythmic vitality. What Green perceives as Brubeck's problematic departure from jazz traditions and his engagement with other musical modalities is certainly echoed elsewhere; while not offering direct commentary on polyrhythm, the title of a review of a 1961 London concert printed in Melody Maker nevertheless expresses anxiety about the value of Brubeck's departure from jazz norms: 'You can never be sure about Brubeck ... Jazz - or party tricks?' (Brown 1961, p. 5).

In contrast to the paucity of references to polyrhythm is the sheer volume of material on Brubeck himself, and it is to this that I will turn initially to provide a context for a more productive sounding of Brubeck's particular deployment of polyrhythm. What emerges if one looks at reviews, features and news items printed in the 1950s and early 1960s is that Brubeck is consistently constructed through two key tropes: difference and modernity. Through the inscription of difference, Brubeck is marked out from other jazz musicians, and his music from that of established jazz tradition and practice, whereas in terms of modernity, Brubeck's own jazz Modernism becomes associated not only with the personalities and practices of 20th-century western art music, but is also situated within a broader cultural context of Modernism. What I will focus on in the first part of my analysis is the construction of Brubeck through a number of consistently repeated elements: the use of academic imagery, references to classical music, the construction of Brubeck as intellectual, and his association with what might be broadly termed 'high art'. These themes often overlap and sometimes contradict, but are consistently drawn upon throughout the late 1950s and early 1960s to construct Brubeck as an artist in the popular imagination. Certainly other themes emerge from this body of literature that similarly work to construct Brubeck in terms of difference: for example, his popular and commercial success, and his stance on racial segregation. However, while these are interesting in their own right, their construction of difference situates Brubeck in relation to discourses that fall outside the scope of the immediate concerns of my analysis. 


\section{Constructing Brubeck}

During the 1950s and early 1960s, Brubeck is consistently constructed with reference to academic imagery in ways that imply his departure from (unstated) jazz norms. Thus a 1961 newspaper profile of Brubeck states, 'Happily married, with five children, Brubeck doesn't even look like a jazz man. With his sixth-form spectacles and his heavy, imposing head, he might pass for a business executive or a youthful professor - which in a way he is' (The Observer, 1961). Preslar (1959), reporting on a performance given to students at Salem College, North Carolina, describes the concert as a 'two-hour lesson in jazz' performed by a 'cast of musical professors', with Brubeck himself as 'the headmaster on the piano'. Of course, coverage of this kind is a reflection of the fact that Brubeck himself was keen to occupy this milieu: early in his career he did plan to teach, offering survey of jazz classes at the University of California in 1949. His two-part article 'Jazz' Evolvement As Art Form', published in Down Beat in 1950 and reprinted for a British audience in Musical Digest (Brubeck 1950a, b), makes pointed reference to the fact that its material was taken from lecture notes prepared for these classes, clearly aligning both Brubeck - and his approach to jazz - with the academy. But perhaps more importantly in terms of this construction, Brubeck pioneered concerts performed at universities for a student audience, a relationship that is cemented in the public imagination by the titles of a series of recordings that emerged from this association: Jazz at the College of the Pacific (1953), Jazz at Oberlin (1953), Jazz Goes to College (1954), Jazz Goes to Junior College (1957). In addition, Brubeck's own musical education is cited frequently in articles and reviews throughout the 1950s and 1960s; mention is often made by journalists of the fact that Brubeck studied music at the College of the Pacific, and then following military service in World War Two, completed postgraduate study at Mills College under the tuition of the French Modernist Darius Milhaud (whose work in bitonality, it should be noted, undoubtedly influenced Brubeck's exploration of polytonality). Brubeck was certainly keen to situate himself in relation to his academic training, and in particular to Milhaud, after whom his first son was named. Thus the Quartet's 1957 promotional booklet, produced by the Derry Music Company, includes a photograph of Milhaud in among those of members of the Quartet. The photograph shows Milhaud working on a score as Brubeck looks on in admiration, and is accompanied by a caption that identifies the composer as Brubeck's 'mentor'. This relationship is picked up by many of the journalists writing about Brubeck, not only in biographical features for magazines such as Time (1954), Esquire (Shaw 1956), Metronome (Ulanov 1953) and Down Beat (Lees 1961), but also in short reviews and news items printed in national and local newspapers; Preslar (1959) for example, writing in the Winston-Salem Journal, feels it worthy of comment that 'Brubeck ... has done graduate music study under some of the top American contemporaries'. Here, indirect reference is made not only to Milhaud but also to Arnold Schoenberg, who taught at Mills College while Brubeck was enrolled there, and with whom Brubeck studied briefly.

References made by journalists to Milhaud serve not only to differentiate Brubeck from other jazz performers by signalling his formal musical training, but also offer tacit validation of his work. By summoning the figure of Milhaud, who was both a respected composer and teacher, Brubeck is marked out as a 'serious' musician through association with the academy and, perhaps more importantly, the traditions of European Modernism. The differential values placed on European 
and American musical traditions, deeply inscribed within both music education and criticism in the United States at this time, had informed public attitudes towards what constituted 'serious' music long before Modernism began to impact upon the work of American composers; put simply, during this period the musical culture of the old world was valued more highly than that of the new world. In the 1930s and 1940s the influx of European performers and composers, as well as professorcomposers such as Schoenberg, Krenek, Toch and Milhaud, helped to inscribe a specifically European model of Modernism into the value system of the American musical establishment; as John Warthen Struble has observed, even up until the 1960s, European musical concepts and techniques served as the yardstick by which many in the American musical establishment measured the achievement of home-grown composers (Struble 1995, p. xv). It is therefore the European tradition of Modernism to which Brubeck is aligned through reference to Milhaud: an association that not only serves to articulate a notion of difference in relation to Brubeck's musical praxis, but also ascribes it with value through the establishment of a relationship with old world culture.

The association with Milhaud is one element of a broader construction of Brubeck that makes much of his relationship to traditions and modes of music other than jazz. Brubeck's relationship with what the popular press loosely terms 'classical' music is heard by writers in his use of counterpoint, and in repeated stylistic references to Bach and Chopin (e.g. Preslar 1959; Elliott 1960; Bryan 1961). As with his use of polyrhythm, in some cases this inscription of difference is constructed as a problematic departure from jazz norms; writing in The Saturday Review, Irving Kolodin (1959, p. 45) comments, 'true jazz devotees consider Brubeck virtually a longhair', thus proposing a generic undecideability that seems to compromise the authenticity of Brubeck's jazz music.

However, there is also a sense in which dominant attitudes towards classical music invest Brubeck's work with additional value. Respect is paid to Brubeck precisely because of the differential values placed on classical and jazz musics. The articulation of the relationship between Brubeck's own musical practice and traditions of European art music serves not only to define and explain Brubeck's musical praxis, but also to confer value and respect through his knowledge of, and association with, that tradition. When Paul Desmond comments in a Down Beat interview that Brubeck plays with 'the vigor of simple jazz, the harmonic complexities of Bartok and Milhaud, the form (and much of the dignity) of Bach and, at times, the lyrical romanticism of Rachmaninoff' (Hentoff 1952, p. 13), his observations are more than merely descriptive: they serve to locate Brubeck in a positive way beyond the dominant discourses of jazz. This realignment of jazz practice becomes highly visible during this period in a number of projects in which Brubeck combined jazz with other musical and performative modes: most notably the symphonic Dialogues for Jazz Combo and Orchestra (1959), and the ballet Pointes On Jazz (1961). Brubeck's departure from the standard modalities of jazz, and in particular his association with 'classical' music is, of course, a two-way street - an association that adds value to his music within certain contexts, but also devalues it in relation to the dominant paradigms of jazz. What is important to note here is not the fact that Brubeck's music draws upon these traditions and styles, but that these are marshalled by both the popular and music presses to construct him, albeit not unproblematically, in terms of difference.

Associated with the foregrounding of Brubeck's musical education in the popular imagination is his construction as cerebral; The Daily Sketch describes him as a 
'bulging-browed intellectual of modern jazz' (Blewett 1962), and Time as 'an intellectual jazzman with an experimental or complex swinging beat' (Time 1954, p. 67). However, a series of potentially problematic associations begins to coalesce around this notion of the intellectual jazzman, relating to the nature of Brubeck's compositional practice. Most importantly the construction of Brubeck as an (educated) intellectual becomes the starting point for a series of distinctions made between the mind and body, worked through in terms of the music itself. Thus Arnold Shaw, writing in 1954 in Esquire magazine, works to distinguish Brubeck's style of music by opposing cognitive with affective pleasures:

Instead of applause, there's thoughtful admiration and appreciation. Instead of sweating, gyrating performers, there's a group of placid 'thinking' musicians. Instead of vivid, aggressive showmanship, there's concentrated 'collective musical thinking.' Instead of excitement, there's something approximating repose. This could be a stony recital of a Beethoven Quartet by the Budapest String Quartet. But it isn't. It's the latest development in instrumental jazz. (Shaw 1954, p. 42)

Brubeck's 'cool' jazz, in its supposed appeal to the intellect rather than the emotions, also runs the risk of denying its audience the normal affective (hot, toetapping) pleasures associated with the music:

The pianist's quartet is his life, a musical laboratory in which to carry out his imaginative probings into the elusive harmonic universe - and the final results, it must be admitted, aren't always to the likings of all jazz lovers. But it must be pointed out that Mr. Brubeck is an individualist who is determined not to have his own playing or that of his quartet curtailed by any 'musical straight jackets'. Behind his thick-rimmed spectacles is an acute mind, a determination to play only what he considers the best and a dry sense of humour 'you may be tempted to tap your feet. Please don't'. (Kilgallon 1959)

In Kilgallon's portrait, Brubeck's individuality and determination are seen to be undertaken at the cost of the popular, crowd pleasing, affective and embodied pleasures of jazz. If Brubeck is being constructed in terms of difference through association with intellect, it is in relation to those bodily, embodied, affective pleasures of jazz that appear to have been displaced by his own experimentation. Such views would seem to be founded on what Gioia (1988) has described as jazz's 'primitivist myth': a mistaken, yet widely held conceptualisation of jazz that only figures and values spontaneous improvisation in terms of direct, emotional communication. In drawing openly upon other compositional methods and styles, Brubeck's own jazz Modernism threatens to destabilise this already problematic notion; consequently Brubeck's positioning of the emotional dimension of jazz is often written about in disparaging terms, summed up by Iain Lang's description of Brubeck as 'Jazz in a grey flannel suit' (Time 1961). Reflecting on Brubeck's audience at a London performance in 1961, Melody Maker's Tony Brown neatly sutures notions of intelligence and lack of emotion, constructing both as essentially problematic within the context of Brubeck's approach to jazz performance:

It was interesting to consider the throng that had assembled to hear Dave Brubeck's Festival concert last Saturday. Conservatively-dressed folk of both sexes, decorous - mostly young, but with a fair sprinkling of the middle-aged. Not a flash harry or a loud-mouth among them and with enough intelligence, apparently, to sit and absorb the Brubeck approach to jazz quietly. Or is it more a flight from genuine jazz than an approach? (Brown 1961, p. 5) 
Similarly, in a review of a London performance shared with the Ronnie Scott Quartet, Peter Clayton compares Brubeck's lack of emotion with the affective appeal of other artists on the bill that evening, commenting 'I don't think even the most fervent admirers of Dave Brubeck claim to be deeply stirred by what he does' (Clayton 1962, p. 15). Brubeck's assumed lack of affective drive is framed by Clayton's more celebratory comments about Scott's performance on tenor sax: 'Ronnie Scott ... blew beefily and with commendable muscle. With emotion, in fact.' Thus Brubeck's music is seen to have an intellectual, cognitive appeal, in contrast to Scott's emotional and embodied ('beefy') approach to jazz.

While the commentary considered above suggests that Brubeck seems to run the risk of losing the 'true' jazz fan by sacrificing emotional content for other musical concerns, his construction as intellectual situates him in closer proximity to other, high status, constituencies. His relationship with the traditions of western art music is seen to naturally make his music of interest to so-called 'serious' musicians: another means by which he is constructed in terms of difference, distinguishing him from other jazz musicians and at the same time conferring value on his praxis. The Australian TV Times writes approvingly:

American pianist Dave Brubeck, who has 'cooled' jazz down about as much as it will go, has been asked to talk to a group of musicians at the Adelaide Arts Festival. These cats are really gone on Brubeck, and have cancelled all their lectures on the night of his concert. Everyone of them is a classical composer. (TV Times 1960)

What is seen as the approval of this high status group confirms a similar status on Brubeck's work, which thus becomes associated in popular journalism with high culture. A number of articles and events in the 1960s casually suture Brubeck and his music into the world of high art, initially by way of association with classical music, compositional (as opposed to improvisational) activity, and 'serious' contemporary music. In this way, Brubeck's work is constructed in terms of art as opposed to entertainment, and thus equated and associated with the work of a range of contemporary artists and composers. This suturing sometimes takes place in very subtle ways; for example, a piece in The Milwaukee Journal from August 1961, covering a high society fundraising event, links Brubeck to fine art by association, as the event at which he played was organised by the Wisconsin Club for Friends of Art in order to raise money to buy a painting or other work of art (Kincaid 1961). This implied or constructed relationship with the visual arts is even more clearly expressed in a 1961 news item from the Sarasota Herald-Tribune's society column, 'On The Party Line'. Here, the newspaper's society correspondent, Flo Schnieder, focuses on forthcoming art activities in a piece entitled 'Modern Art, Cool Jazz Meet':

Big week coming up ... there's the Fourteenth Annual Art Symposium at the Ringling Museum (most important seminar of its kind in the southeast and bound to fill our town to over-flowing with the famous in the art world) ... the Dave Brubeck quartet performance on Thursday.... (Schneider 1961)

The column lists visiting luminaries from the art world, including Philip Guston, Musa McKim and Adja Yunkers, who were all involved with the symposium at the Ringling Museum of Art. While not mentioned in the article, on display at the Museum at this time was an exhibition of the Sidney Janis painters: Albers, Baziotes, Gorky, Gottlieb, Guston, Kline, De Kooning, Motherwell, Pollock 
and Rothko. Constructed by the article, the artistic space in which 'Modern Art, Cool Jazz Meet' clearly locates Brubeck within the same milieu as the giants of American abstract expressionism. Furthermore, Schneider makes the assumption that Brubeck's place within this milieu will ensure his appeal extends and translates to those interested primarily in the fine arts:

It seems highly appropriate (since the world of art and music are so closely related) that this week brings the 'cool' music of Dave Brubeck's quartet at a time when exponents of modern art are also in town. ... With Thursday a 'free' night at the symposium, we presume the auditorium will attract many of the visiting (and local) artists. ... The entire west coast of Florida seems to be snapping up tickets for Brubeck's first appearance here. They'll be coming down from Clearwater to the north, and up from Ft. Myers to hear this exponent of 'far-out jazz'. (Schneider 1961)

Similar connections can be observed elsewhere, which extend associations with Brubeck to both fine art, and major figures in the history of American music. In 1966, Danbury State College, Connecticut, hosted a 20th Century Arts Festival, the purpose of which was, according to the College newspaper, 'to promote interest and understanding of twentieth century art media. Included in this will be new directions in the fields of music, painting and sculpture' (The Echo 1966, p. 1). The festival opened with performances of works by Varèse and Cage, followed by an evening celebrating the work of Charles Ives. Other events included an exhibition of painting and sculpture, and a talk by Brubeck on new directions in jazz. It is a mark of Brubeck's status and public persona at this time that he is described in the college newspaper not as a jazz musician, but as 'one of America's leading contemporary performing artists' (The Echo 1966, p. 1). But perhaps more importantly, Brubeck's photograph shares the front page of the College newspaper with Charles Ives, suggesting not necessarily a direct equivalence, but certainly a comparability that indicates the two men occupy the same extended milieu. Elsewhere, in an article marking the centenary of Debussy's birth, Brubeck's appraisal of the French composer appears alongside others written by Darius Milhaud, John Cage and Edgard Varèse (Listener's Guide 1962, pp. 12-13), again demonstrating the way in which Brubeck is situated in relation to traditions of music other than jazz.

What can be seen from this brief analysis is the way in which Brubeck is constructed by the music press and the popular press in terms of difference, in both positive and negative ways; thus difference is framed as failure, primarily by critics who seek to locate Brubeck in relation to the dominant tenets of jazz practice, while for some writers Brubeck's relationship with other musics, and by association with other art forms, confirms value on both his persona and praxis. The themes used by the press to construct Brubeck were, of course, a response to many things, including Brubeck's own publicity material and, importantly, his whiteness. However, in the sense that Brubeck was neither a College Professor nor a classical musician, these articles fail to resolve the problem of Brubeck. This journalistic and critical failure is an important indicator of the fact that Brubeck's music could not be fully understood within the existing critical discourses relating to jazz. Yet at the same time, there is as sense in which the press's focus on difference is an attempt to articulate an alternative context for Brubeck's music, within which it might be better understood. An essential part of this constructed difference undoubtedly turns on Brubeck's association with Modernism. Emerging from this context, two cultural artefacts prove particularly useful in situating Brubeck within a cultural history of 
Modernism: Joan Miró's Painting (1925), which featured as the cover art for the 1961 Columbia album Time Further Out, and Brubeck's Oakland house at 6630 Heartwood Drive, which featured in a number of articles on Brubeck published in the 1950s. It is my contention that the connections to be made between the music, the Oakland house and the Miró painting provide a meaningful context for a better understanding of Brubeck's polyrhythm by situating his musical praxis within the discourses of Modernism. However, I offer neither the house nor the painting as keys to unlocking single, definitive and final reading of Brubeck's polyrhythmia; rather each provides a means by which we might return to Brubeck's work in order to release a potentiality neglected by existing critical perspectives. My analysis of the Oakland house and album artwork is informed by the work of Drummond (1979), Williams (1989), Lunn (1985) and Piper (1993), in identifying the displacement of hegemonic models and forms, the exploration of alternative structural and organisational models, and the surfacing and foregrounding of repressed and invisible structural codes, as general features of Modernism. While this list of features is by no means exhaustive, I argue it nevertheless provides a productive context in which to further explore Brubeck's use of polyrhythm.

\section{Brubeck House}

In 1949 Brubeck commissioned San Francisco architect Beverley Thorne to build a family home on a steep, rocky piece of land in Oakland, overlooking San Francisco Bay (Figure 1). Following its completion in 1954, the house received a significant amount of popular press coverage, with dedicated feature articles appearing in San Francisco newspapers such as The Examiner (House 1954), the News-Call Bulletin (O'Flynn 1960), in advertising features in Business Week (1958) and the Republic and Gazette (1958), and within biographical portraits of Brubeck that appeared in music magazines such as Record Whirl (Hentoff 1955) and Jazz World (1957) and in general interest publications such as Time (1954) and Good Housekeeping (Drury 1958). The house, while in sympathy with the surrounding natural environment of rocky outcrops and pine and eucalyptus trees, was nevertheless a bold statement of Modernist design. Thorne, like many other architects working in Northern California at this time, absorbed and reworked the architectural vocabulary of the International Style, particularly in his use of industrial materials. Letters held in the Brubeck Collection at the University of the Pacific ${ }^{2}$ show that at the time the Oakland house was built, Thorne was signing himself 'Architect Thorne', after the practice he had observed in Europe. By adopting the strategy of dropping his first name in favour of his professional title, Thorne was clearly seeking to declare his relationship with the Modernist tradition (Serraino 2006, p. 154). In the 1940s, there were a number of important modern architects working and teaching in the Bay area, including Eric Mendelssohn and Serge Chermayeff. Drawing on the ideas of these influential teachers, Thorne developed an approach to architecture underpinned by his belief that 'architecture is the structure' (Serraino 2006, p. 164). What marked Thorne's work out from that of other architects of the period was his commitment to the steel frame, an industrial material not previously used for domestic buildings. Thorne's design solution to the challenges offered by the steep land on which Brubeck's home was to be built was a dramatic cantilevered construction, anchored to the rock of the site. With rooms that hang 20 feet from the ground, 


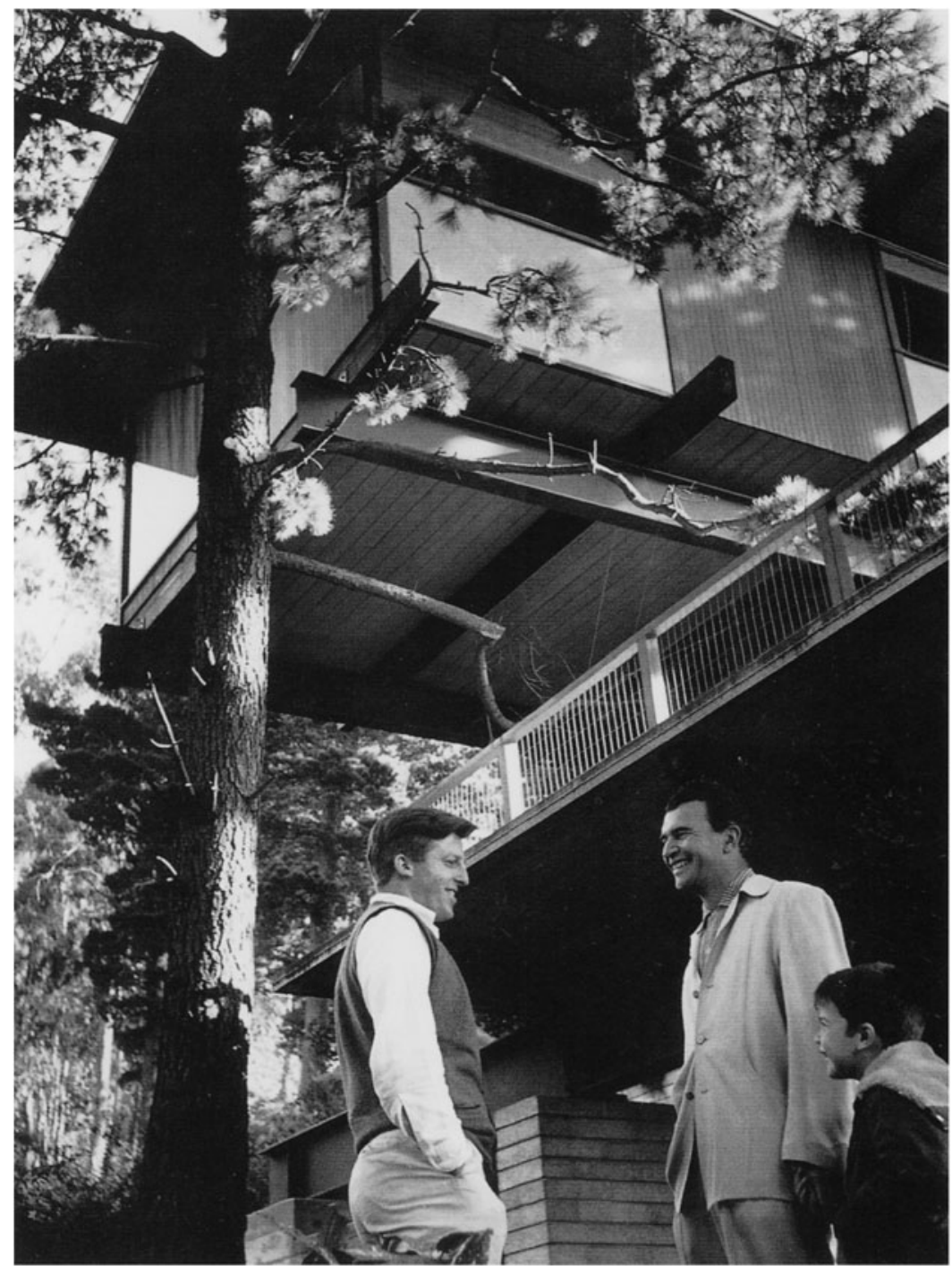

Figure 1. Architect Beverley Thorne and Dave Brubeck at 6630 Heartwood Drive, 1954. (Reproduced by kind permission of Beverley Thorne. Image courtesy of Pierluigi Serraino.)

the building's underbelly is clearly exposed, revealing the steel frame that provides its fundamental structure (see Figure 2).

The building declares its Modernist pedigree in a number of ways. Its design clearly breaks with vernacular domestic architecture in its radical foregrounding of structure and materials. In revealing its own steel supports, rather than cladding them or losing them within the fabric of the building, the Brubeck House expresses Thorne's commitment to what he terms the honesty of structure, and the honesty of the materials: 'I just die when they [the steel frames] go up. They are so beautiful, especially if they are painted [with] red oxide, and there is the honesty of it ... You can't screw around with it. Then you close it, and then you kind of lose it a little bit' (Serraino 2006, p. 164). Thorne's focus on the structure, his use of new construction 


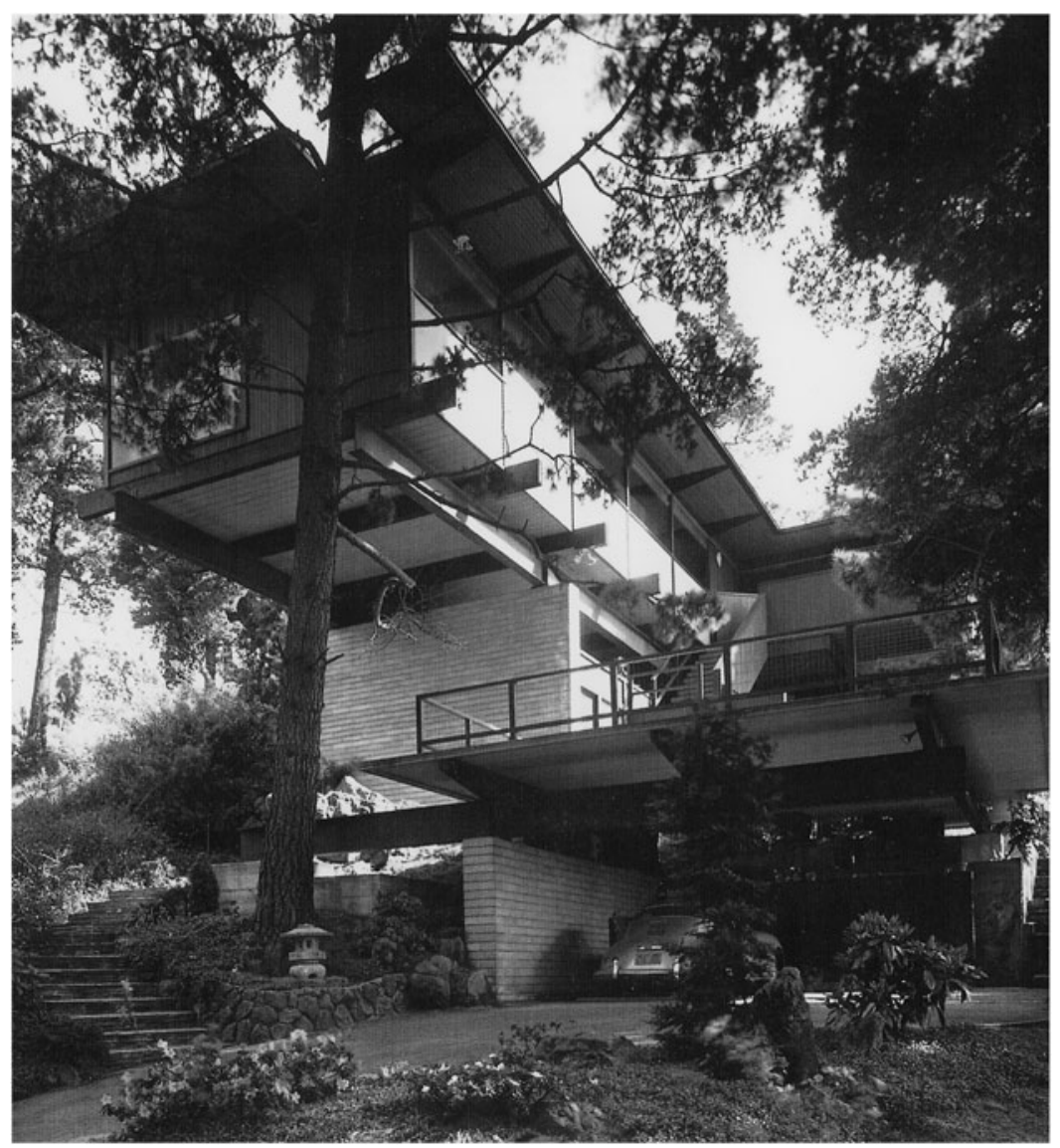

Figure 2. Brubeck House, 6630 Heartwood Drive. (Reproduced by kind permission of Beverley Thorne. Image courtesy of Pierluigi Serraino.)

methods and industrial materials such as steel and plate glass, work to render opaque the invisible structural and material codes of architecture. In particular, the building's clarity of form, the emphasis on materials and geometric forms, its rejection of decorative motifs and designs, all work not only to delineate space, but also to render that very space opaque. Through the unadorned simplicity and abstract geometry of Thorne's design, expressed most clearly through the revelation of its steel frame, the building's organising structure declares itself, and in so doing takes on a sculptural quality: a vertically oriented space delineated by horizontally layered rectilinear forms. Through the criss-crossing of steel girders, onto which modules are superimposed, the structure of the building comes through loud and clear, as does its relationship with the space it occupies. That is to say, the modernity of Thorne's design lies partly in its very declaration of three-dimensional space, as the linearity of steel frame, and volume of the room modules, render visible space ordinarily conceptualised as an invisible and merely neutral container for architectural forms; it is in this sense that the building adheres most radically to Modernism's drive to foreground repressed and invisible structural codes. The building thus adheres to what Lunn identifies as Modernism's 'intense concern with the mediation of "content" by form' (Lunn 1985, p. 2). 
The functionality of the space within the house also reveals Modernist influences. The traditional arrangement of static rooms is to some extent challenged by Thorne's design, which allows for a certain spatial fluidity as a response to overlapping functions: the house is both a domestic space and a workplace, and its design carefully negotiates the demands placed upon a family by the work patterns of a professional musician. In addition to soundproofed walls and floors, sliding soundproofed doors serve to separate music, living and sleeping areas when required. The design of the Brubeck House also responds to technological developments of the period with the inclusion of a recording studio - a facility made possible by the introduction of the portable quarter-inch tape recorder. The Columbia albums Brubeck Plays Brubeck (1956) and Brubeck Plays and Plays and Plays (1957) were both recorded here, and letters written by Brubeck in the early 1950s to the manufacturers of tape recorders reveal a serious interest in the possibilities offered to the performing artist by portable recording technology $\mathrm{y}^{3}$; an interest further evidenced by the approximately 650 quarter-inch reel-to-reel tapes made by and for Brubeck, currently archived at the University of the Pacific.

In its efficient use of designed space, the house seems to live up to the ideal of Le Corbusier's machine for living. However, the focus on managing function sometimes manifests itself in terms of containment and, in particular, in relation to jazz and children. In addition to the soundproofing that serves to contain jazz activity within the space of the house, the building was provided with two separate entrances: one providing access to living quarters for family and friends, and another offering access to 'visitors on a professional mission in connection with Brubeck's career' (House 1954). In relation to the containment of children, glass panelled doors to their bedrooms 'permit a quick check up on activities', while a mud room allowed them to clean up before coming indoors.

However, such open celebration of Modernism was not without risk. As the architectural critic Kenneth Cardwell recently commented, 'There was a big reaction against the International Style, that it was mechanistic, machine-like, factory-like. And people did not want to live in factories' (Serraino 2006, p. 84). The building's radical modernity is rendered less frightening than it might otherwise be, and its occupants less frightening by association, through references to traditionalism: 'In all the plans Mrs. Brubeck worked closely with architect B. D. Thorne. ... The dramatic, sheer lines of the contemporary home built to follow the contour of the lot belie the comforts one finds within. Ollie [Iola Brubeck] refers to their home as having "the comforts of an old farm house"' (O'Flynn 1960). The house's relationship to the natural environment is also important in negotiating the controlling nature of Modernism, and its industrial pedigree; thus an advertising feature for the Bethlehem Steel Corporation, the supplier of materials for the building's frame, describes the home as Brubeck's 'tree house' (Business Week 1958, p. 93) while the San Francisco News Call Bulletin points out that 'Only two trees were removed from the rocky wooded lot for the construction of the Dave Brubeck home in Oakland. Allowance was made in the shape of the roof for a towering pine tree' (O'Flynn 1960).

Thus reportage of the house fulfils an important function in negotiating Brubeck's relationship with Modernism, and also jazz. Through his association with Thorne's building, and his subsequent tacit participation in an essentially Corbusian 'machine for living' project, Brubeck is clearly aligned with (European) Modernism. However, the radical nature of both is countered by the focus placed by the articles on family life. At the same time, the house domesticates jazz through 
the emphasis placed on family and by the controlling influence exercised by Modernism. Part of the newsworthiness of the house lies in its declaration of Brubeck's family man persona and value system. Thus Nat Hentoff comments, 'He loves to stay at home with his family so much, as a matter of fact, that he arranges his bookings so that he spends at least six months of the year or often more in the San Francisco bay area. He does this even though it means monetary sacrifice' (Hentoff 1955, p. 27). In this way, Hentoff constructs the house as an expression of Brubeck's prioritisation of family above commercial concerns. This image of domestic stability has news value precisely because it is inscribed against a popular understanding of jazz that constructs its performers in less positive ways; Brubeck's constitutive other is the nomadic, nocturnal jazzman of the popular imagination. Writing in Good Housekeeping, Michael Drury comments, 'His private life is as surprising and inscrutable as his music. He wants no part of the diversions that devil many jazzmen: he rarely drinks; regards the use of drugs as a form of cheating; has a personal, almost mystical, religious bent; and lives quietly with his wife and five small children. ... The Brubecks' family life is both decent and delightful. ...' (Drury 1958, p. 53). Drury's implicit approval of Brubeck's lifestyle choices demonstrates the fact that even during the late 1950s, jazz still carried disreputable associations. Normalised as the soundtrack of crime, delinquency, drug addiction and sexual immorality by the mainstream media, jazz music's negative associations - many of which were racially charged - undoubtedly continued to inform a popular understanding of the music and its key figures in this period. Thus the construction of Brubeck as a clean-living family man clearly differentiates him from other white musicians such as Art Pepper or Chet Baker, whose lifestyles were much more clearly aligned with the music's disreputable and dangerous image. Furthermore, Brubeck's apparent sacrifice of financial reward in favour of domestic life signals a musician who appears to be less caught up in the strictly commercial world of jazz than his peers. As a powerful symbol of Brubeck's lifestyle choices and value system, the house thus plays an important part in enabling him to circumvent the potentially negative associations of the musical practice with which he is primarily associated. Brubeck might still be a jazzman but, as the Wolverhampton Express and Star's John Chaplin delicately puts it, 'is an antithesis of the rip-roaring jazz personality' (Chaplin 1961). This disassociation from the rip-roaring, bedevilled image of the jazz musician, and from unrestrained commercial ambition, both support and articulate an alternative cultural space for Brubeck, and in hosting this complex set of overlapping and intertwining themes, it is the house that proposes Modernism as the alternative context for Brubeck as a 'serious' musician. At the same time, Brubeck's association with jazz is mediated by Modernism: Brubeck's jazz Modernism is not the wild, free play suggested by Pollock's abstract expressionism a common touchstone for writers thinking about the relationship between modern jazz and painting (e.g. Mandeles 1981). In this instance, jazz seems to be aligned with the hard-edged, geometrical abstractions that informed the International Style, and which were later to re-emerge in the 1960s via Minimalism. Press coverage of the building can thus be seen to negotiate the potentially problematic nature of Brubeck's jazz music, which somehow embraces elements of Modernism, and does not appear to conform to the dominant model of jazz as unfettered, unconscious free expression.

In the way in which Thorne's building foregrounds materiality and structure, and in the way in which it both delineates space and makes that space opaque, 
the house is consonant with the ways in which Brubeck's music makes audible its own temporal framework, and the materiality of its musical sounds: issues to which I will return shortly. As I hope to demonstrate, key elements of Brubeck's musical praxis - his use of unusual time signatures and, importantly, polyrhythm are thrown into sharper relief when auditioned within the cultural milieu suggested by his association with Modernism.

\section{Album covers}

Beyond the common experimental nature of Thorne's architecture and certain elements of Brubeck's music, there is a mutual resonance with Modernism which can be explored further through consideration of the artwork chosen for the Quartet's album covers of the late 1950s and early 1960s. Brubeck's own understanding of his music's relationship with the Modernist canon is perhaps signalled most clearly by the daring choice of 'difficult' artwork for the five Columbia albums that explored the use of time signatures unfamiliar in jazz: Time Out (1959), Time Further Out: Miro Reflections (1961), Countdown: Time In Outer Space (1962), Time Changes (1964) and Time In (1966). Each breaks with the normal convention of the period of featuring a photograph of the performers, replacing this instead with abstract artworks. Time Out, the first of the series, features an abstract design by Neil Fujita, Columbia's in-house art director at the time. Countdown: Time in Outer Space features Franz Kline's dramatic 1959 canvas, Orange and Black Wall, while Time Changes uses Sam Francis's energetic 1960 painting The White Line. The series closes with Time In (1966), which breaks with the abstract expressionism of the two previous album covers in favour of a severe Minimalism reminiscent of the work of Gene Davis. However, perhaps the best known and arguably most striking of all these album covers was the second in the series, Time Further Out: Miro reflections, which features a Miró canvas from 1925, simply titled Painting. Set against a densely textured coffee-coloured background, solid abstract forms in white, green and red combine with numerals, and both broken and continuous linear forms (Figure 3). According to Brubeck's liner notes for the 1996 re-release of Time Further Out, his intention had been to use Miró's painting for the first album in the series, Time Out, but he was unable to secure the necessary permissions. However, through the help of Xenia Cage, former wife of composer John Cage, and the Pierre Matisse Gallery, permission was obtained from Miró for the painting to be used as the cover art for Time Further Out. Thus, it could be argued, Miró's painting has a special status within this series of albums as its originary image.

The album's sub-title, Miro Reflections, establishes a clear link with the cover art, while the main title refers to the previous album in the series, suggesting perhaps increased gravitation of the Quartet's music towards 'far out' jazz. Brubeck himself reflects on the choice of this image and the relationship between the artwork and his music in the original liner notes to Time Further Out:

To explain the relationship of the Miró painting to the music is not a simple task. I can point out the obvious links between the numbers in the upper right hand corner of the painting and the time signatures of each piece of the album. There is a more tenuous link in the Miró abstract forms, suggesting human figures moving in a visual rhythm which could be interpreted as a jazz quartet. However, beyond these objective relationships of symbols and figures, I feel that in Mirós painting he has expressed in visual terms my own approach to music - that is, a search for something new within old forms, an unexpected perspective, a surprising order and inner balance that belies the spontaneity of composition. 


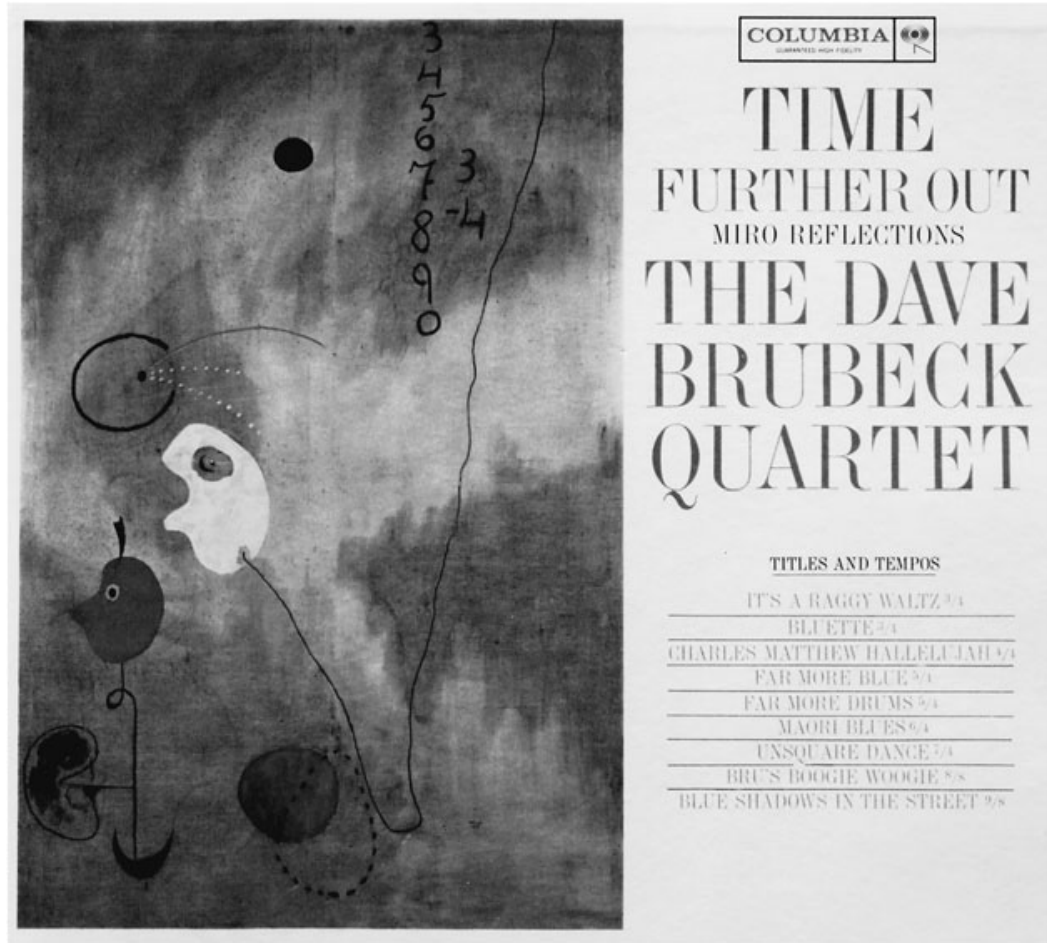

Figure 3. Dave Brubeck Quartet (1961), 'Time Further Out' LP sleeve. (Sony BMG Music Entertainment).

What this makes clear is that Brubeck understands the relationship between the painting and his music to extend beyond the specific representational links he establishes between particular elements of the painting, the Quartet, and its music. That is to say, Brubeck sees in Miró's painting a visual expression of his own musical praxis. In eschewing images of the music's performers in favour of abstract artworks, Brubeck is purposefully crafting what we might loosely term 'concept' albums. However, the images do not provide an explanation for or a key to the music, but rather serve to locate the music within a broader cultural sphere, and thus offer roughly parallel figurations of what Brubeck feels the Quartet's music sets out to explore.

The painting featured on the cover of Time Further Out belongs to a group of over 100 canvases completed by Miró between 1925 and 1927, categorised by Dupin (2004) as 'oneiric' paintings. While these paintings seem to both draw upon, and refer to, hallucinations and dreams, they are marked by a degree of abstraction that distinguish them from Miró's earlier works, and from the work of his surrealist peers. As Soby has pointed out, in the paintings preceding this period, Miró 'had painted more or less objectively, each picture depicting a separate imagery, whether based on actual experience and tangible appearances or proceeding directly from hallucinations and dreams' (Soby 1959, p. 45). However, as Dupin states, 'In 1925 Miró dropped the mode of fantastic representation, by means of which he had been 'translating' into ideographic and poetic language the objects, scenes, landscapes, and beings most familiar to him' (Dupin 2004, p. 120). This increased movement towards abstraction takes two 
forms: a reduction of foreground forms or figures, and a concomitant increased presence of the background. Dupin's commentary on these backgrounds not only offers an interesting way of considering them, but is in itself is an indicator that these are not the well behaved, neutral or naturalistic backgrounds of other painters; thus he suggests that the oneiric paintings produced between 1925 and 1927 are 'dominated by an omnipresent background' (Dupin 2004, p. 121). While some of these backgrounds were painted in tempera, Miró sometimes used bare canvas, or added turpentine to produce dribbly washes, such as that seen in Painting (1925). Dupin comments:

these backgrounds have a curious animation that does much to permeate the oneiric atmosphere of these pictures. ... The jumbled, sometimes washed-out backgrounds - into which the colors seem to have thrown themselves haphazardly while the painter was asleep - invest the canvases with a singular character of something missing, a kind of negative vibration that carries us into an uncomfortable prehistorical domain. On these backgrounds Miró gives himself over to an allusive graphism. Extracted from his Carnets, strange signs and forms, puzzling shapes, come to be - but only just. ... (Dupin 2004, p. 121)

In the relationship it establishes between figure and background, Miró's Painting expresses what Brubeck perhaps means by an 'unexpected perspective'. That is to say, in emptying out the foreground and increasing the visibility of its background, the painting resonates with Brubeck's own repositioning of the rhythmic element in jazz, and with Thorne's delineation of space, whereby formerly invisible structural codes are now rendered visible. In its break with existing structural and organisational models, modern art's rejection of perspective, as a means of structuring painting, led to a flattening of picture space. This can be observed in Miró's work here, as the background of the painting begins to occupy its own space; in Painting, the background is not a well behaved, transparent support for the foreground subject, but rather becomes a material and structuring presence in its own right. In this reorientation and recasting of the relationship between background and foreground, Miró's canvas responds to the drive within Modernism not only to displace painting's dominant structural models, but also to foreground its construction, materiality, and the invisible codes that govern both. One can see, therefore, that the painting's open declaration of structure and materiality resonate with Brubeck's use of time signatures that foreground and make audible the formerly well behaved and inaudible work of rhythm within jazz, which is predominantly conceptualised as a support or background for the 'foreground' of the music: the instrumental solo or ensemble chorus.

The question to be asked now is whether or not the Modernism suggested by Thorne's architecture or Miró's painting provides a convincing and productive context for a further analysis of Brubeck's oeuvre, and in particular his use of polyrhythm. To address this question, in the analysis that follows I would like to consider Brubeck's use of 'unusual' time signatures and his deployment of polyrhythm within the context offered by Modernism rather than jazz musicology.

\section{‘Unusual' time signatures}

Brubeck, of course, was neither the first nor the only musician to explore nonstandard time signatures in jazz: in 1957 Max Roach released Jazz in 3/4 Time, 
celebrated as the first album devoted entirely to what was still an unusual time signature in jazz composition. While aware of the work of Roach and others exploring this field, Brubeck's engagement with 'unusual' time signatures was motivated by a perception that jazz, nevertheless, continued to be dominated by one particular time signature. However, while Brubeck justifies his adoption of time signatures unfamiliar in jazz in terms of a progressive break with what he perceived as jazz's standard model of 4/4 time (Jazz Casual 1961), there are other ways in which the temporal dimensions of his praxis might be situated within the discourses of Modernism. Within the context of jazz, time signatures such as 5/4 ('Take Five') and 11/4 ('Eleven Four') have the effect of making music's temporal dimension audible. By structuring the temporal dimension of jazz rhythmically in this manner, Brubeck displaces the untroubling $4 / 4$ that served as a commonly accepted time signature for most mainstream jazz during this period, and replaced it with something that renders music's rhythmic dimension opaque. Here rhythm seems to be in tension with those other elements of the music that are more readily conceptualised as its 'foreground': for example, improvised performances - and in particular those of Desmond and Brubeck. The established foreground-background relationship between rhythm and other elements of music begins to take on a different quality when the rhythm is complex and uneven, and consequently begins to assume a foreground position within the sonic matrix. In this way sound produced by the rhythm section, which underpins the constant progression of solos, is no longer relegated to the background, but instead declares its own concrete materiality, as does the background of Miró's Painting. Thus Brubeck's foregrounding of rhythm through the use of 'unusual' time signatures can be understood as a foregrounding of music's own structural codes - a foregrounding of both the structure and materiality of music and its temporal nature.

With the inclusion of unfamiliar, unjazzy time signatures, what might have been an untroubling, smooth flowing temporal medium becomes turbulent and audible. In Brubeck's music, time itself becomes material, as duration is audibly patterned or segmented. The passage of time is now marked, and thus duration is no longer simply a transparent, neutral container for the sonic events created by the improvising soloist. This aspect of the music accords with what Lunn has identified as one of the defining characteristics of Modernism, namely 'techniques of de-familiarising the object-world' (Lunn 1985, p. 2). Consequently, one important effect of Brubeck's adoption of complex and uneven time signatures is to draw attention to the music's own concrete temporal materiality, in the same way that Thorne's building declares its own concrete articulation of space. This was certainly understood by Brubeck, who comments in his liner notes to the 1962 album Countdown - Time in Outer Space:

The concept of music as the only art that captures Time has long fascinated me. Music is as concerned with Time, as architecture is with Space. Sound shatters time into fragments, which the musician has arranged in such patterns of periodicity that we say the music has rhythm. When these patterns fall in such precise relationships to one another that they seem to follow a natural law, we say that the music has a pulse of its own.

Intentionally or not, when auditioned within the context of jazz, Brubeck's music denaturalises the music's rhythmic foundations, rendering its temporal dimension audible, and thus revealing what Williams refers to as 'the non-natural status of language' (Williams 1989, p. 34). In announcing the passage of time by rendering it 
opaque, the adoption of these time signatures also creates a certain textual selfawareness in the music, once again aligning Brubeck's praxis with one of the key features of Modernist art. This tendency can be seen to manifest itself in Brubeck's work in other ways: for example, in the explicit listing of time signatures against composition titles on the cover of Time Further Out, or in the metatextual commentary on jazz form offered by the Octet's gently pedagogical montage of stylistic variations on 'How High The Moon' from 1948. This is music that is aware of its own status as music: music that is aware of its own musicality, its own structure, its own materiality. This is music that knowingly declares its sonic and temporal materiality, rather than simply entraining both as the inaudible supports of emotional pleasures.

\section{Polyrhythm}

Brubeck's work with multiple rhythms dates back to the very beginning of his career. In his 1946 composition 'Sun Up', six rhythm changes are combined through linear montage, creating what Storb describes as 'a mosaic-like effect' (Storb and Fischer 1994, p. 29). While here the inscription of rhythmic difference is undertaken in a horizontal dimension, with the piece shifting from one rhythm to another as it develops in time, in his work with the Octet in the late 1940s, and subsequently with the Trio and the Quartet, Brubeck explores rhythm in a vertical dimension through the use of polyrhythmic superimposition. Thus, for example, on the Time In recording of 'Cassandra', Brubeck plays in 3/4 throughout, against 4/4 rhythm backing, while on the Countdown recording of 'Why Phillis Waltz', Brubeck plays in 4/4, drummer Joe Morello in 3/4, while bassist Eugene Wright shifts between 4/4 and 3/4. Through the inscription of difference, both linear montage and polyrhythmic superimposition render the music's rhythmic dimension opaque. But in the case of polyrhythm, this declaration of difference is perhaps at its most radical when asynchronous rhythmic streams emerge from a common starting point. This form of rhythmic divergence can create a sense of temporal tension or turbulence, as differences between rhythms are not always resolved, and multiple rhythms may co-exist independently, at least for a time. Thus on Time In's title track, Morello can be heard playing a fairly frantic 3/4 on drums, against Brubeck's 4/4 stride piano solo, which in turn is played in what is effectively double time against Wright's ponderous bass line. The heterogeneity of rhythms and tempos is particularly stark, in this instance, when listening to Brubeck's rhythmically insistent stride solo against Morello's crisp, waltz-time stick-work; at its most radical, the rhythmic divergence is reminiscent of Conlon Nancarrow's experiments with player pianos. This sonic heterogeneity resonates with Miró's Painting, whose various visual elements are not unified, but are in themselves expressive of heterogeneity, as marks, numerals and background all vie for attention on their own terms. Such asynchronicity gives the music a sense not only that it is falling apart and deconstructing as one listens, but is also proliferating. It is perhaps not surprising, therefore, that many jazz critics, who had traditionally valued 'tightness' and 'communication' as worthy attributes of ensemble playing, simply heard Brubeck's asynchronous polyrhythmic superimpositions in terms of musical failure.

What this particular approach to polyrhythm requires is a certain metronomic insistence that once again could not be understood within the existing critical 
discourses relating to jazz during this period. An illustration of this is offered by a 1961 article published in the jazz magazine Coda. Here, Paul Wright perceives a difference between Brubeck's music of the 1940s and early 1950s, and more recent work: 'Brubeck, one of the original avant-gardists in jazz (I firmly believe his 1947 recordings with his octet parallel those of Davis Nine a few years later), has declined in recent years.' Wright identifies this decline as a 'tendency to produce music of a slick yet banal quality', which he attributes primarily to Joe Morello's 'facile antiseptic drumming'. He continues, 'With Morello, as soon as he begins, you can immediately sense a rigid, impenetrable confidence which unavoidably means, in jazz at any rate, a cool, calculated performance, free from error, and pretty well free from warm, spontaneous emotion' (Wright 1961, p. 19).

What this critic senses as failure in terms of jazz, and consequently dismisses, might however be more fruitfully discussed in other ways. Paradoxically, what Morello's rhythmic insistence allows is, in fact, rhythmic departure, as Brubeck may repeatedly leave and rejoin the rhythm established by the drummer. Morello is the rock-solid metronome against which Brubeck can drift, and without which there can be no sense of divergence or departure. Certainly, this drifting does not create the affective pleasures that jazz is normally associated with; however, it does not mean the device is without musical value. In negotiating the heterogeneity of multiple temporal frames, Brubeck expands or unfolds time in the same way that the Cubists opened up space in their paintings. While accessible, not only does Brubeck's use of polyrhythm have the potential to render one aspect of musical temporality opaque, but his recasting of time as a drifting multiplicity, rather than as linear and metronomic, destabilises the very notion of a coherent, consistent temporal base, rendering temporality neither comforting, unified, nor ultimately knowable. This challenge to any notion of temporal stability clearly aligns Brubeck's use of polyrhythm with those works of early Modernism that fundamentally challenged existing conceptualisations of space and time. For Lunn, 'the use of synchronous montage as an alternative to merely linear additive time' (Lunn 1985, p. 2) is indeed a defining characteristic of Modernism. When resituated in relation to Braque and Picasso's exploration of space in painting, or in relation to Joyce's exploration of language and temporality in literature, the potentiality of Brubeck's music is radically transformed; put another way, a more productive auditioning of Brubeck's polyrhythmia is achieved through alignment with the key works of the Modernist canon rather than with the personalities and practices of modern jazz. This is not to claim a place for Brubeck within this canon, but rather to suggest that when resituated within another context - the context of Modernism - we are able to explore aspects of the work overlooked or dismissed by the dominant discourses of jazz criticism. This radical potential of Brubeck's polyrhythmia was not addressed by contemporary critical commentary, and for some writers of the time Brubeck's music was simply a failure as jazz; with no conceptual vocabulary in place to deal with his use of polyrhythm other than existing jazz musicology, all Brubeck's critics could hear were insufficiencies. However, his construction by the popular press, with its focus on difference and modernity, can be seen as an attempt to articulate an alternative context for Brubeck's music outside the established discourses of jazz criticism. In addition to being one of its fundamental pleasures, the polyrhythmic aspect of Brubeck's work offers a highly sophisticated and radical exploration of music's temporal dimensions - an aspect of the music that I propose is best understood within the context of Modernism. 


\section{Acknowledgements}

Research for this article was undertaken with the aid of a Brubeck Collection Research Travel Grant. The author would like to gratefully acknowledge support provided by the Holt-Atherton Special Collections Department, University of the Pacific, and by Beverley Thorne and Pierluigi Serraino.

\section{Endnotes}

1. Interviewed by Ralph Gleason (Jazz Casual 1961).

2. Brubeck Collection, Holt-Atherton Special Collections, University of the Pacific. MS 1.A.1.37.
3. Brubeck Collection, Holt-Atherton Special Collections, University of the Pacific. MS 1.A.1.9.

\section{References}

Blewett, D. 1962. 'Lullaby of Brubeck', Daily Sketch, 16 November

Brown, T. 1961. 'Jazz - or party tricks?', Melody Maker, 25 November, p. 5

Brubeck, D. 1950a. 'Jazz as an art form', Musical Digest, 16, pp. 160-4

Brubeck, D. 1950b. 'Jazz' evolvement as art form', Down Beat, 27 January, pp. 12-15 [part 1]; 10 February, pp. 13-18 [part 2]

Bryan, J. 1961. 'A Bach-like Brubeck', San Francisco Examiner, 15 October

Business Week. 1958. 'Dave Brubeck and his "tree house"', Business Week, 24 May, p. 93

Chaplin, J. 1961. 'Brubeck found a fourth dimension in creative works', Wolverhampton Express and Star, 6 December

Clayton, P. 1962. 'Time and emotion', Jazz News, 28 November, p. 15

Drummond, P. 1979. 'Notions of avant-garde cinema', in Film as Film: Formal Experiment in Film 1910-1975. Arts Council of Great Britain, pp. 9-16

Drury, M. 1958. 'The private life of Dave Brubeck', Good Housekeeping, February, pp. 52-211

Dupin, J. 2004. Miró (Paris, Flammarion)

Elliott, G.A. 1960. 'Symphony joins Brubeck jazz combo in rare event Friday', Grand Rapids Press, 6 November

Fox, C. 1961. 'Review, Berstein Plays Brubeck Plays Bernstein, by Dave Brubeck Quartet/New York Philharmonic', The Gramophone, February, p. 461

Gioia, T. 1988. The Imperfect Art: Reflections on Jazz And Modern Culture (Stanford, Stanford Alumni Association) Green, B. 1961. 'Jazz-Fanciers' idol', The Observer, 26 November

Hentoff, N. 1952. 'Altoist Paul Desmond is vital factor in success of Dave Brubeck Quartet', Down Beat, 18 April, p. 13

Hentoff, N. 1955. 'Inside Dave Brubeck', Record Whirl, May, pp. 26-31

House, G. 1954. 'Jazz and rocks in a Hilltop House', San Francisco Examiner (Modern Living Section), 5 December

Jazz Casual 1961. The Dave Brubeck Quartet. KQED TV, San Francisco, 17 October. Available on: John Coltrane Quartet/Dave Brubeck Quartet. 2001. Ralph Gleason's Jazz Casual (Andorra, Idem Home Video [video: DVD])

Jazz World. 1957. 'Brubeck vs. the critics', Jazz World, July, pp. 61-3

Kilgallon, L. 1959. 'Night with the jazz stars', Evening Citizen, 29 September

Kincaid, D. 1961. 'Bal du lac Fills Wisconsin Club for Friends of Art Benefit', The Milwaukee Journal, 21 August

Kolodin, M.I. 1959. 'Music to my ears, 'Faust' with a flair - jazz with the Philharmonic', Saturday Review, 26 December, pp. $44-5$

Lees, G. 1961. 'About this man Brubeck', Down Beat, 22 June, pp. 22-4

Listener's Guide. 1962. 'Debussy', Listener's Guide, November, pp. 10-14

Lunn, E. 1985. Marxism and Modernism: An Historical Study of Lukács, Brecht, Benjamin, and Adorno (London, Verso)

Mandeles, C. 1981. 'Jackson Pollock and jazz: structural parallels', Arts Magazine, October, pp. 139-40

O'Flynn, K.M. 1960. 'Bringing the outdoors indoors', San Francisco News-Call Bulletin, 14 January

Piper, A. 1993. 'The logic of Modernism', Callaloo, 16.3, pp. 574-8

Preslar, L. 1959. 'Brubeck and crew play here', Winston-Salem Journal, 7 March

Republic and Gazette. 1958. 'Dave Brubeck and his "tree house"', Republic and Gazette, 23 June

Schneider, F. 1961. 'On the party line', Sarasota Herald-Tribune, 16 April

Serraino, P. 2006. NorCalMod: Icons of Northern California Modernism (San Francisco, Chronicle Books)

Shaw, A. 1954. 'The cool generation', Esquire, May, pp. 42-104

Shaw, A. 1956. 'West Coast jazz', Esquire, September, pp. 79-127

Soby, J.T. 1959. Joan Miró (New York, MOMA) 
Storb, I., and Fischer, K.G. 1994. Dave Brubeck: Improvisations and Compositions - The Idea of Cultural Exchange (New York, Peter Lang)

Struble, J.W. 1995. The History of American Classical Music: MacDowell Through Minimalism (London, Robert Hale)

The Echo. 1966. '20th century arts festival', The Echo - Danbury State College, 3/10, 11 March, p. 1

The Guardian. 1958. 'The art of Dave Brubeck. Rhythm on rhythm', The Guardian, 17 February

The Observer. 1961. 'Profile: Dave Brubeck', The Observer, 19 November

Time. 1954. 'The man on cloud no. 7', Time, 8 November, pp. 67-76

Time. 1961. 'Successful failure', Time, 15 December, p. 41

TV Times. 1960. Untitled news item, TV Times, 4 March

Ulanov, B. 1953. 'A talk with Dave Brubeck', Metronome, April, pp. 13-30

Williams, R. 1989. The Politics of Modernism: Against the New Conformists (London, Verso)

Wright, P. 1961. 'Brubeck: a personal opinion', Coda, January, pp. 19-20

\section{Selected discography}

Dave Brubeck Octet. Dave Brubeck Octet featuring Paul Desmond, Cal Tjader, David Van Kreidt, Dick Collins. Fantasy Records, OJCCD-101-2. 1991

The Dave Brubeck Quartet, Time Out. Columbia, CL 1397. 1959

The Dave Brubeck Quartet, Time Changes. Columbia, CS 8927. 1964

The Dave Brubeck Quartet, Time In. Columbia, CS 9312. 1966

The Dave Brubeck Quartet. Time Further Out: Miro Reflections, CS8490. [1996 CD reissue: Columbia/Legacy, CK64668] 